\title{
Silver Ion Microplates for Immunoassays
}

BioTechniques 30:1340-1351 (June 2001)

\section{Matthew R. Bonen, Steven A. Hoffman, and Antonio A. García \\ Arizona State University, Tempe, AZ, USA}

\section{INTRODUCTION}

Since the late 1950s, when the work of Yalow and Berson $(26,27)$ first illuminated the possibilities of immunoassays, immunodiagnostic techniques based on the specific interaction of antibody and antigen have become of paramount importance in the clinical, agricultural, food, veterinary, and environmental sectors. In 1996, it was estimated that the worldwide market of im munoassay products was $\$ 10$ billion in the clinical sector alone, and increasing at an annual rate of $10 \%$ (3). This market is driven by an ever-increasing desire for assays of greater specificity and sensitivity, at reasonable financial costs. It is in this environment that the specific and irreversible interaction between avidin or streptavidin and biotin has found widespread use.

Streptavidin, a close relative of egg white avidin, is expressed in Streptomyces avidinii (8), and both avidin and streptavidin exhibit an affinity for biotin on the order of $10^{15} / \mathrm{M}$. The streptavidin-biotin system has become a widely used tool of molecular biology in such applications as affinity chromatography, cytometry, nucleic acid research, and diagnostics $(4,23,24)$. A common immunological procedure calls for the use of streptavidin-coated microplates, which are used to capture either biotinylated antibodies or antigens. Because the assay is based on the interaction of streptavidin and biotin, universal kit assay formats are possible. These universal assays are also the basis of many automated immunological testing systems (6). A format utilizing a microplate ELISA can measure a wide variety of analytes using a dual antibody or "sandwich" immunoassay $(15,22)$. In this system, the primary (capture) antibody is biotinylated. The antibody is bound to the walls of the microplate wells through the interaction of the biotin label with the streptavidin-coated surface.

The choice of a streptavidin-coated solid support is made to overcome the limitations present in the direct antibody coating of polystyrene supports. The direct adsorption of monoclonal antibodies can result in unreliable or nonuniform coating of the solid support or deactivation of the antibodies $(2,5)$. With antibodies bound to the plate through the mediation of a streptavidinbiotin linkage, the risk of antibody deactivation is greatly reduced because the biotin moiety is linked to the antibodies at a point distant from the antigen recognition sites (16).

Research examining the behavior of biotin has found that immobilized soft metal ions such as silver and platinum will bind biotinylated compounds strongly and, in this case, reversibly. This research has been done with both immobilized metal affinity chromatography (IMAC) $(7,11,14)$ and paramagnetic particles (18). The application of immobilized soft metal ions in a universal ELISA format holds promise as an alternative to streptavidin. Streptavidin is also a large molecule (60 kDa), which limits the number of molecules that may form a monolayer on a given surface area. It is possible to bind more silver ions to a given surface due to the higher surface density possible with dramatically smaller silver ions.

Previous studies to determine the 
chemistry of $\operatorname{Ag}(\mathrm{I})$ ion immobilization for a polyacrylamide chromatography packing help guide the procedures used for the work on microplates. X-Ray Photoelectron spectra and analytical chemical measurements (7) show that silver ions can be immobilized at a high loading capacity, with no detectable level of oxide formation, using thiourea as a ligand and glutaraldehyde as a spacer molecule and covalent linker for thiourea.

In this study, the direct immobilization of a model biotinylated molecule, biotin-labeled horseradish peroxidase (bHRP) onto microplates is studied as a first step in the development of a new metal ion chemistry for solid-phase im munoassays. The specificity of bHRP over HRP immobilization is compared for modified plate surfaces. Appropriate controls with glutaraldehyde and thiourea modified plates show that silver ions are needed to immobilize bHRP.

Along with biotinylated proteins, capture antibodies can also be immobilized on silver ion microplates. The im munoassay used to measure the amount of active antibodies immobilized is based on the capture of HRP by biotinylated anti-HRP antibodies. In this case, since the antigen being captured is HRP, it can be directly detected by a solution of ABTS in a chromogenic reaction in a fashion similar to standard ELISAs.

\section{MATERIALS AND METHODS}

Surface amine-containing microplates were obtained from Corning Costar (Corning, NY, USA). Glutaraldehyde (Grade II, 25\% aqueous) and thiourea used for microplate surface activation were purchased from Sigma-Aldrich (St. Louis, MO, USA). Silver nitrate was obtained from Fisher Scientific (Pittsburgh, PA, USA). During the activation procedure, the microplates were sealed with a polyethylene film, Titer-Tops ${ }^{\mathrm{TM}}$ (Diversified Biotech, Boston, MA, USA). The remainder of the materials used for the biotin-binding assay was obtained from Sigma-Aldrich. This includes the bHRP used to verify silver loading in the amine microplates, which was used in a solution of $50 \mathrm{mM}$ phosphate buffer (PB) at pH 7.0 with $1 \%$ Tween $^{\circledR}$ 20 added (PB-Tween). HRP was also obtained from Sigma-Aldrich.

A model 3508 Lab-Line Dual Action Shaker was used to agitate the glutaraldehyde during polymerization. The assays were performed using a Benchmark Microplate Reader, a Microplate Washer Model 1575, and Microplate Manager software (all from Bio-Rad Laboratories, Hercules, CA, USA).

\section{Silver Ion Activation of Amine Microplates}

Silver ions were introduced to the surface of a microplate through the direct chemical modification of the plate surface. The Corning Costar amine microplates were activated directly with soft metal ions. Since the plate has $2 \times$ $10^{13}$ reactive amine sites per square centimeter, it was possible to bind a high density of silver ions for use in an immunoassay. The activation protocol for the immobilization of silver ions to the amine microplates is shown in Figure 1.

In the microplate activation procedure, $25 \%$ glutaraldehyde was polymerized at $70^{\circ} \mathrm{C}$ for $24 \mathrm{~h}$ in a water bath. During the polymerization procedure, the glutaraldehyde was agitated continuously with a dual action shaker. The amine microplate was rinsed with deionized water, and then $200 \mu \mathrm{L}$ polymerized glutaraldehyde were added to each well. The plate was then covered and sealed using Titer-Tops. The glutaraldehyde was incubated in the microwells at $37^{\circ} \mathrm{C}$ for $24 \mathrm{~h}$ using a gravity flow incubator. After this time, the glutaraldehyde was removed from the plate. The plate was rinsed three times with deionized water to remove any remaining glutaraldehyde, and then 200 $\mu \mathrm{L}$ of a 1-M aqueous thiourea solution were added to each well. The plate was covered and sealed, followed by another 24-h incubation at $37^{\circ} \mathrm{C}$. After this step, the thiourea solution was removed and the plate was rinsed three times with deionized water. A 1-M aqueous solution of silver nitrate was then added, and a final step of $24 \mathrm{~h}$ exposure at $37^{\circ} \mathrm{C}$ followed. The plate was then rinsed with deionized water three times and allowed to dry overnight. Once dry, the plates were resealed and stored at room temperature in opaque sleeves. These plates
Table 1. Custom Automated Plate-Washing Protocol

\begin{tabular}{|lc|}
\hline Washing Step & $\begin{array}{c}\text { Duration } \\
\text { (s) }\end{array}$ \\
\hline Dispense & - \\
Pause & 10 \\
Agitate & 10 \\
Aspirate and dispense & - \\
Pause & 10 \\
Agitate & 10 \\
Aspirate and dispense & - \\
\hline
\end{tabular}

are very stable because no measurable degradation of performance was observed, even after storage at room temperature or $4^{\circ} \mathrm{C}$ for several months.

\section{Biotin-Binding Enzyme-Linked Assay}

Before all tests, the silver ion microplates were hydrated and washed. Liquid transfer in the microplates was accomplished with a Microplate Washer. In the hydration protocol, the plates were filled with $50 \mathrm{mM} \mathrm{PB}$ and allowed to stand for $10 \mathrm{~min}$. The plates were then emptied by inversion and rinsed twice, again using $\mathrm{PB}$.

Once the plates were prepared for the assay, the bHRP was diluted in PBTween, with the Tween 20 added to the solution to minimize the effects of hydrophobic interactions on the assay. The bHRP dilutions were added to the plates with a multichannel pipet (Brinkmann Instruments, Westbury, NY, USA) and were allowed to stand in the plates for $1 \mathrm{~h}$. This incubation was done at room temperature, as were the remainder of the steps in all the assays performed in this research. During all incubations, the plates were covered using Corning Costar microplate lids. Following this $1-\mathrm{h}$ incubation, the plates were emptied by inversion. The plates were then washed with PB-Tween in the Microplate Washer using a custom washing protocol detailed in Table 1 .

Detection of the bound bHRP was accomplished using a colorimetric reaction with 2,2'-azino-bis(3-ethylbenzthiazoline-6-sulfonic acid) diammonium salt (ABTS). To create the substrate solution, $17 \mathrm{mg}$ ABTS were added to 
$100 \mathrm{~mL} 50 \mathrm{mM}$ citrate buffer at $\mathrm{pH} 5.0$. Immediately before use, $100 \mu \mathrm{L} 3 \%$ hydrogen peroxide was added to the solution to begin the colorimetric reaction. A Benchmark microplate reader was used for kinetic readings of the change in absorbance of the solution at $415 \mathrm{~nm}$ over time. The readings were performed using the Microplate Manager software, which controlled the plate reader and imported the data to the computer for analysis. Figure 2, a-c, details the biotin-binding assay procedure.

To ensure the validity of the data, various controls were used. The silver-activated microplate strips were compared to unmodified amine strips and strips modified with glutaraldehyde and thiourea, but lacking silver (denoted as GT). Because the plates are in the stripwell format, it was possible to run the experiment and the appropriate controls on the same plate in a side-by-side fashion. Two plates were prepared where silver ion strips were alternated with GT and amine strips to form plates with side-by-side controls. The initial solution of bHRP was selected to be quite dilute so that an examination of the endpoint of the assay with only eight dilutions (maximizing the number of assays) could be performed on a single plate. This allowed for a total of four as-

\section{Step I: Glutaraldehyde Polymerization}

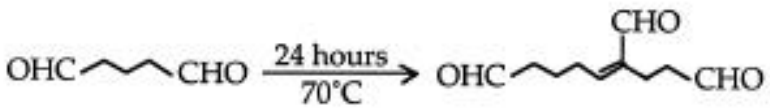

Step II: Amine Activation

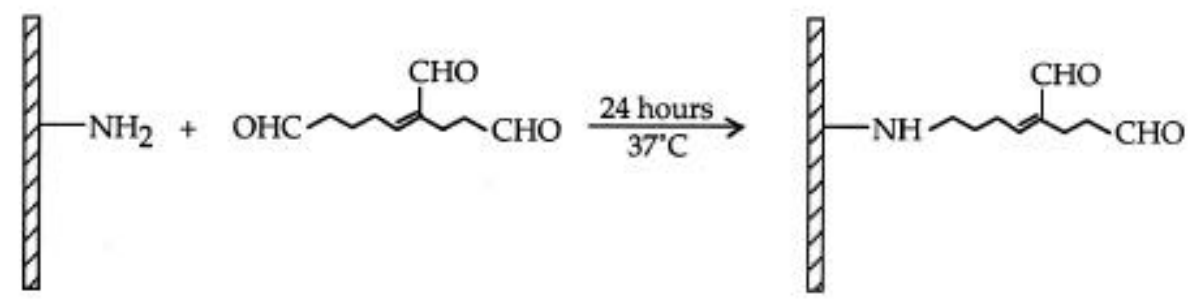

Step III: Addition of Thiourea

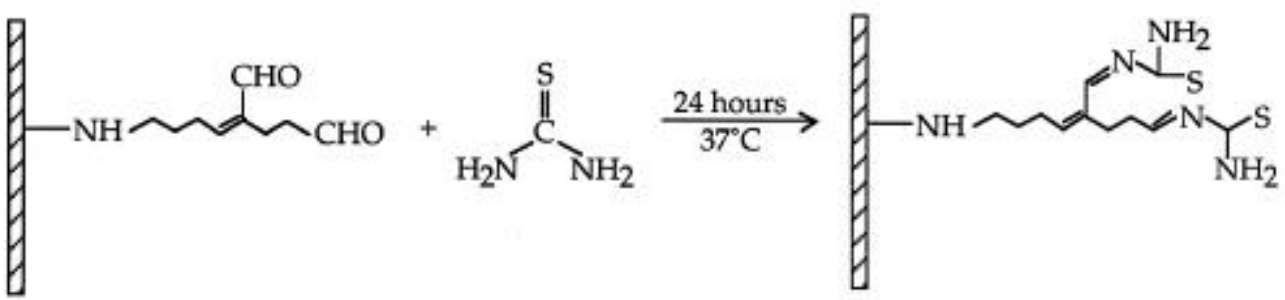

Step IV: Addition of Silver Nitrate

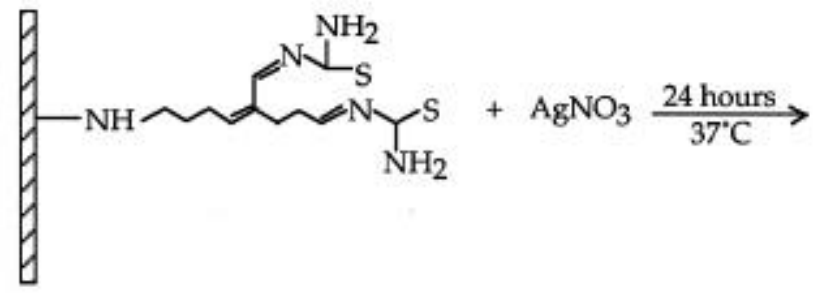

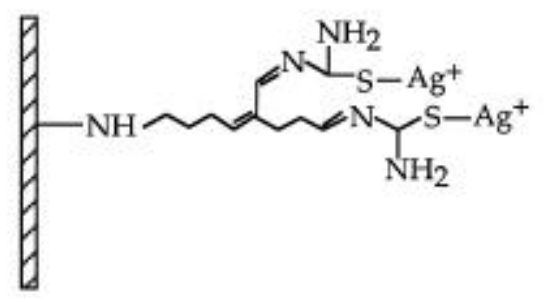

Figure 1. Illustration of the series of chemical modification steps to generate a silver coating on the inner surface of the microplate wells. 


\section{Research Report}

says per plate, giving eight replicates of the desired data. The plate setup is shown in Figure 3, and the dilution values for the biotinylated enzyme are given in Table 2.

The biotin-binding assay was performed according to the standard procedure. The plates were hydrated with $\mathrm{PB}$, and then rows 2-12 were filled with $150 \mu \mathrm{L}$ PB-Tween. Row 1 was filled with $150 \mu \mathrm{L}$ of the initial dilution of bHRP. The bHRP was added to row 2 by mixing $150 \mu \mathrm{L}$ of the initial solution with the dilution buffer in the wells. The solution was then introduced into the remaining rows of the plate through the use of doubling dilutions. After covering the plate and allowing the solutions to incubate for $1 \mathrm{~h}$, the plate was washed using the standard washing protocol. Using the standard detection method, the kinetic rate data for the assays were collected.

One further test was necessary to eliminate the possibility that the HRP, instead of the biotin label, was interacting with the silver ions. To ensure that the biotin label was responsible for the binding to the silver ion wells, bHRP was tested in a same plate side-by-side assay with HRP. The expected result was that the biotinylated enzyme would stay on the well surface, while the unlabeled enzyme would not.

A complete silver ion-activated microplate was used for this control experiment. An aliquot of $150 \mu \mathrm{L}$ of the initial dilution of HRP was placed in wells A1 and A2, and $150 \mu \mathrm{L}$ of the initial dilution of bHRP were placed in wells A7 and A8. The solutions were made with PB-Tween, which was also used as the dilution buffer for this assay. The initial solutions were diluted down the two columns using doubling dilutions, then brought back to the top to A3 and A4 for HRP and A9 and A10 for bHRP. The solutions were then diluted down the columns, again using doubling dilutions.

\section{Biotin-Binding Immunoassay}

The immunoassay procedure is also shown in Figure 2, i-iv, with the antibodies added first to coat the wells during a 1.5-h incubation. The antibodies were introduced into wells in a solution of $50 \mathrm{mM}$ PB-Tween at $\mathrm{pH}$ 7.0. After washing the plate with PB-Tween using the protocol detailed in Table 1, an aqueous solution of HRP was added in various dilutions for a 1 -h incubation.
PB-Tween buffer solution was added to dilute the solution containing HRP. To ensure the validity of the data, several controls were used. Nonspecific

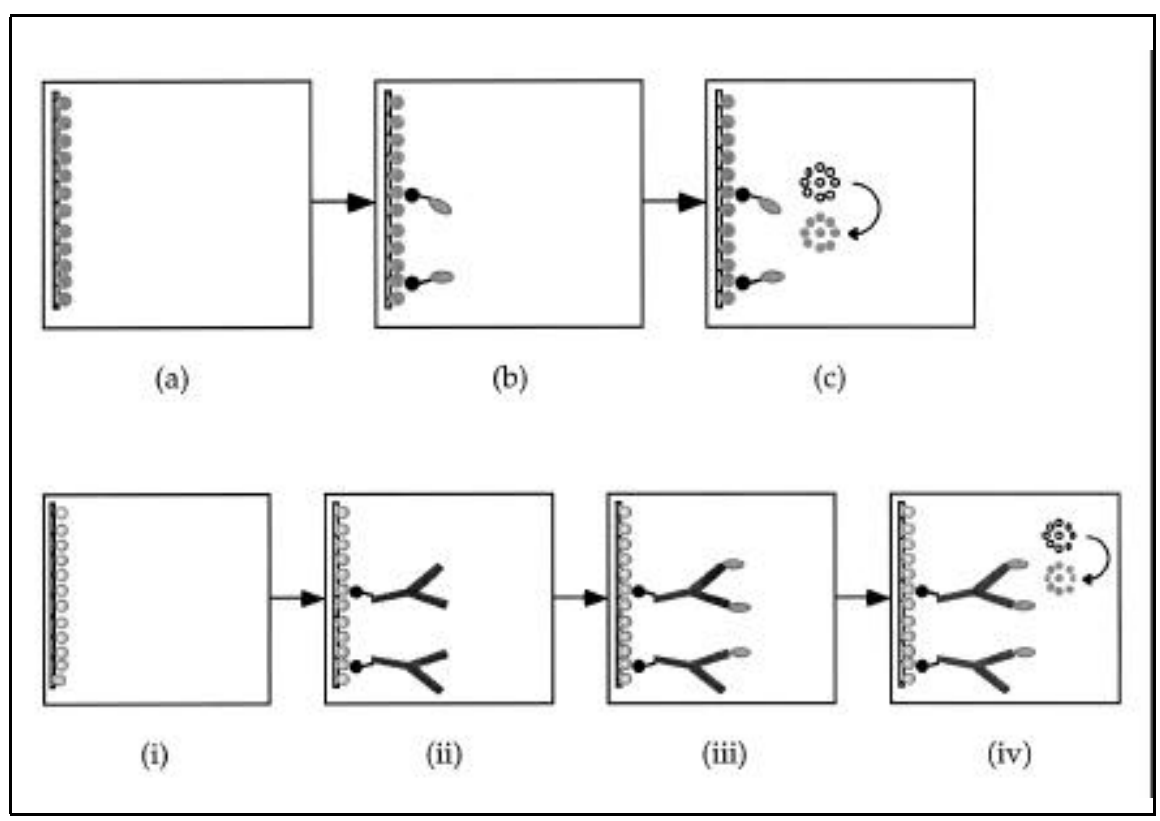

Figure 2. Schematic comparison of steps used to determine the binding capacity of microwell surfaces for HRP and anti-HRP. Panels a-c illustrate how microwells containing a silver ion coating can immobilize bHRP. (a) The modified surface of the microwells contains silver ions (shown as small gray spheres). (b) bHRP attaches to surface silver ions through the biotin moiety. The addition of ABTS substrate is used to detect the presence of immobilized HRP (c) because the enzyme oxidizes this molecule, creating a chromogenic compound detected by light absorbance at $415 \mathrm{~nm}$. Similarly, panels i-iv illustrate how microwells containing a silver ion coating can immobilize biotin-labeled anti-HRP antibody.

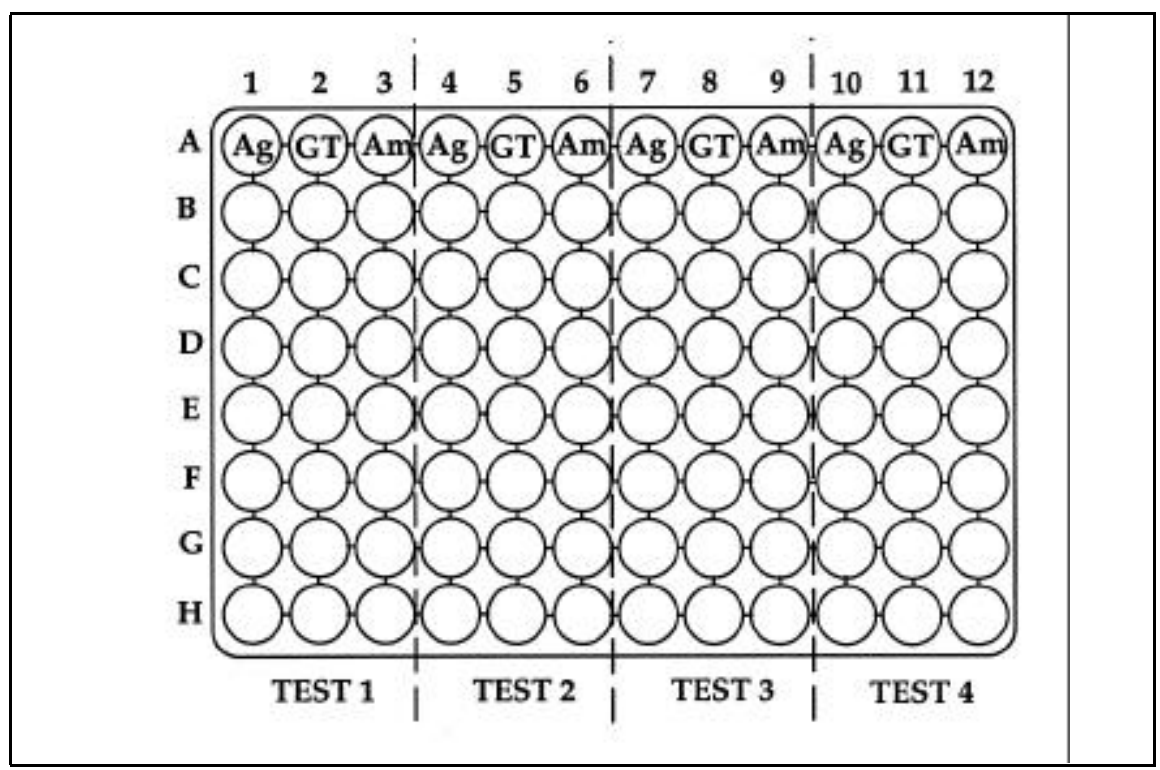

Figure 3. Arrangement of microwell strips for determining the amount of HRP (biotin-labeled and unlabeled enzymes) immobilized onto the surface of the microwells. Am refers to wells that are unmodified and contain surface amine groups. Wells modified with glutaraldehyde and thiourea, but lacking silver ions, are designated as GT, while wells modified with these chemicals and exposed to silver ions are designated as Ag. 


\section{Research Report}

Table 2. Biotin-Binding Assay Replication Dilutions

\begin{tabular}{|lcc|}
\hline $\begin{array}{l}\text { Dilution } \\
\text { Number }\end{array}$ & $\begin{array}{c}\text { bHRP } \\
\text { (g/well) }\end{array}$ & $\begin{array}{c}\text { bHRP } \\
\text { (mol/well) }\end{array}$ \\
\hline 1 & $1.20 \mathrm{E}-07$ & $2.67 \mathrm{E}-12$ \\
2 & $6.00 \mathrm{E}-08$ & $1.33 \mathrm{E}-12$ \\
4 & $3.00 \mathrm{E}-08$ & $6.67 \mathrm{E}-13$ \\
8 & $1.50 \mathrm{E}-08$ & $3.33 \mathrm{E}-13$ \\
16 & $7.50 \mathrm{E}-09$ & $1.67 \mathrm{E}-13$ \\
32 & $3.75 \mathrm{E}-09$ & $8.33 \mathrm{E}-14$ \\
64 & $1.88 \mathrm{E}-09$ & $4.17 \mathrm{E}-14$ \\
128 & $9.38 \mathrm{E}-10$ & $2.08 \mathrm{E}-14$ \\
\hline
\end{tabular}

adsorption of HRP to the microplate was determined by alternating antibody-coated strips with well strips containing only the silver ion coating, and no antibody was added. Detection of the captured HRP was performed using standard enzymatic methods as previously described.

\section{Determination of Optimum Capture Antibody Concentration}

As shown in Figure 2, the first step in the procedure is the immobilization of capture antibody. To determine the optimum concentration of capture antibodies, a diagonal test microplate dilution procedure was used (3). This procedure helps to visualize the dynamic detection range in that various concentrations of the capture antibody and the capture target are used. The checkerboard assay shown in Figure 4 was performed with biotinylated, anti-HRP antibodies, diluted in PB-Tween to a concentration of $0.012 \mathrm{mg} / \mathrm{mL}$. An aliquot of $150 \mu \mathrm{L}$ of this solution was added to the first column of a silver ion plate. The remainder of the wells was filled with $150 \mu \mathrm{L}$ PB-Tween as the dilution buffer. Using doubling dilutions, the antibody was introduced across the plate in decreasing concentrations (Table 3 ). The plate was then covered and allowed to incubate at room tem perature for $1.5 \mathrm{~h}$.

After incubation, the plate was washed using PB-Tween in the Microplate Washer running the plate washing protocol used in all experiments and detailed in Table 1. Mixing
Table 3. Diagonal Test Assay Relationship between Dilution Number and Resultant Antibody Concentration

\begin{tabular}{|lc|}
\hline $\begin{array}{c}\text { Dilution } \\
\text { Number }\end{array}$ & $\begin{array}{c}\text { Biotinylated } \\
\text { anti-HRP } \\
\text { antibody }(\mathbf{m g} / \mathbf{m L})\end{array}$ \\
\hline 1 & $1.20 \mathrm{E}-02$ \\
2 & $6.00 \mathrm{E}-03$ \\
4 & $3.00 \mathrm{E}-03$ \\
8 & $1.50 \mathrm{E}-03$ \\
16 & $7.50 \mathrm{E}-04$ \\
32 & $3.75 \mathrm{E}-04$ \\
64 & $1.88 \mathrm{E}-04$ \\
128 & $9.38 \mathrm{E}-05$ \\
256 & $4.69 \mathrm{E}-05$ \\
512 & $2.34 \mathrm{E}-05$ \\
1024 & $1.17 \mathrm{E}-05$ \\
2048 & $5.86 \mathrm{E}-06$ \\
\hline
\end{tabular}

HRP in PB-Tween then created a solution of HRP, the capture target. An aliquot of $150 \mu \mathrm{L}$ of this solution was added to the wells of Row A on the microplate, and then this solution was diluted down the plate using doubling dilutions of $150 \mu \mathrm{L}$ PB-Tween in the remainder of the wells. The amount of
Table 4. Diagonal Test Assay Relationship between Enzyme Amount and Dilution Number

\begin{tabular}{|lcc|}
\hline $\begin{array}{l}\text { Dilution } \\
\text { Number }\end{array}$ & $\begin{array}{c}\text { HRP } \\
\mathbf{( g )}\end{array}$ & $\begin{array}{c}\text { HRP } \\
\text { (mol) }\end{array}$ \\
\hline 1 & $1.13 \mathrm{E}-06$ & $2.56 \mathrm{E}-11$ \\
2 & $5.63 \mathrm{E}-07$ & $1.28 \mathrm{E}-11$ \\
4 & $2.81 \mathrm{E}-07$ & $6.40 \mathrm{E}-12$ \\
8 & $1.41 \mathrm{E}-07$ & $3.20 \mathrm{E}-12$ \\
16 & $7.03 \mathrm{E}-08$ & $1.60 \mathrm{E}-12$ \\
32 & $3.52 \mathrm{E}-08$ & $8.00 \mathrm{E}-13$ \\
64 & $1.76 \mathrm{E}-08$ & $4.00 \mathrm{E}-13$ \\
128 & $8.79 \mathrm{E}-09$ & $2.00 \mathrm{E}-13$ \\
& & \\
\hline
\end{tabular}

enzyme present for each dilution step is given in Table 4 . The enzyme solution was incubated in the plate at room temperature for $1 \mathrm{~h}$, followed by another standard washing procedure (Table 1).

Detection of the captured antigen is performed using the ABTS detection solution described earlier and in a manner similar to the method described above. Measurements of the change in the absorbance of the solution at $415 \mathrm{~nm}$ began immediately, using the kinetic program in the reader at room temperature. Measurements were taken every 30 $\mathrm{s}$ for $10 \mathrm{~min}$, and these data were used to

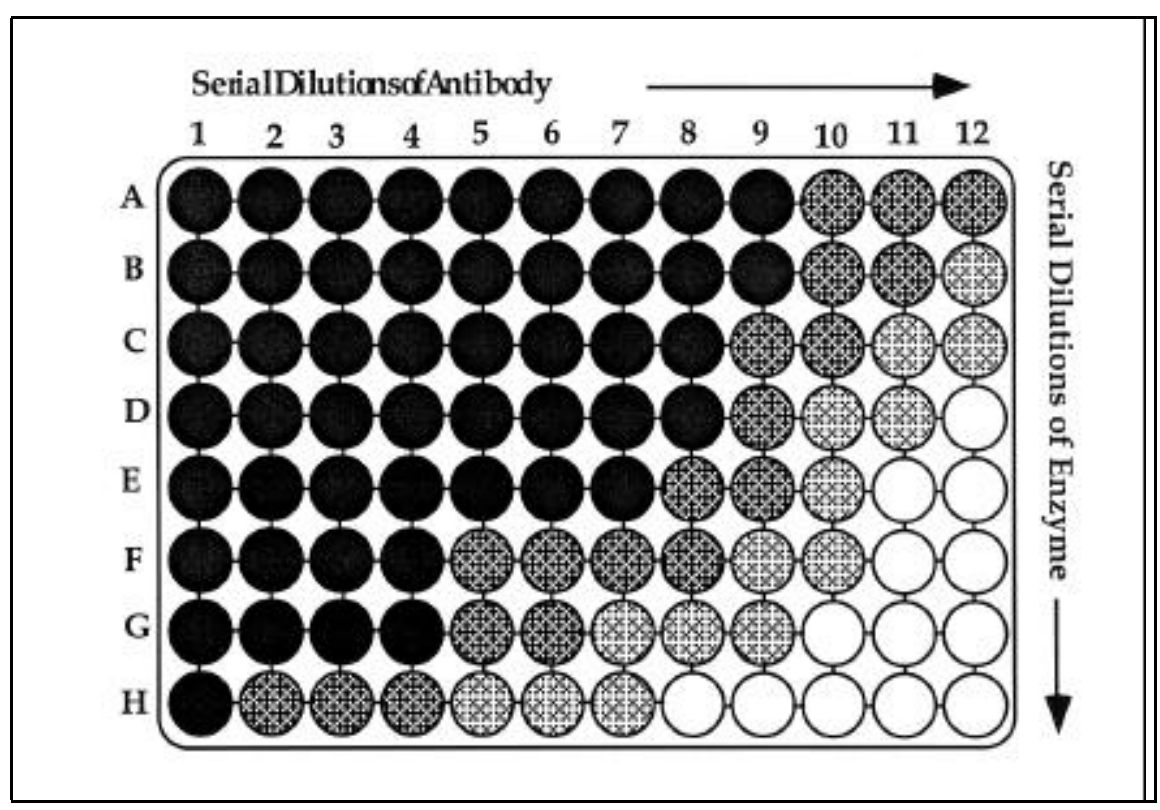

Figure 4. A schematic of the diagonal test assay format. At the top left-hand corner (microwell A1), the highest concentration of antibody and enzyme are added. The bottom right hand corner (microwell H12) contains the lowest concentration of added enzyme and antibody. 
Table 5. Antibody Immobilization Assay Relationship between Enzyme Amount per Well and Enzyme Dilution Number

\begin{tabular}{|lcc|}
\hline $\begin{array}{c}\text { Dilution } \\
\text { Number }\end{array}$ & $\begin{array}{c}\text { HRP } \\
\text { (g/well) }\end{array}$ & $\begin{array}{c}\text { HRP } \\
\text { (mol/well) }\end{array}$ \\
\hline 1 & $1.20 \mathrm{E}-06$ & $2.73 \mathrm{E}-11$ \\
2 & $6.00 \mathrm{E}-07$ & $1.37 \mathrm{E}-11$ \\
4 & $3.00 \mathrm{E}-07$ & $6.83 \mathrm{E}-12$ \\
8 & $1.50 \mathrm{E}-07$ & $3.41 \mathrm{E}-12$ \\
16 & $7.50 \mathrm{E}-08$ & $1.71 \mathrm{E}-12$ \\
32 & $3.75 \mathrm{E}-08$ & $8.53 \mathrm{E}-13$ \\
64 & $1.88 \mathrm{E}-08$ & $4.27 \mathrm{E}-13$ \\
128 & $9.38 \mathrm{E}-09$ & $2.13 \mathrm{E}-13$ \\
256 & $4.69 \mathrm{E}-09$ & $1.07 \mathrm{E}-13$ \\
512 & $2.34 \mathrm{E}-09$ & $5.33 \mathrm{E}-14$ \\
1024 & $1.17 \mathrm{E}-09$ & $2.67 \mathrm{E}-14$ \\
2048 & $5.86 \mathrm{E}-10$ & $1.33 \mathrm{E}-14$ \\
4096 & $2.93 \mathrm{E}-10$ & $6.67 \mathrm{E}-15$ \\
8192 & $1.46 \mathrm{E}-10$ & $3.33 \mathrm{E}-15$ \\
16384 & $7.32 \mathrm{E}-11$ & $1.67 \mathrm{E}-15$ \\
32768 & $3.66 \mathrm{E}-11$ & $8.33 \mathrm{E}-16$ \\
\hline
\end{tabular}

establish the initial kinetic rate of the development of color in the solution.

\section{Antibody Immobilization and Enzyme Capture Assay}

Once the optimum concentration of capture antibody was determined, the silver ion-coated microplates were tested using the antibody immobilization and antigen capture protocol given in Figure 2. First, the silver ion plate was hydrated with PB solution. Following this, $150 \mu \mathrm{L}$ of the biotinylated antiHRP antibody solution, at a strength of $0.012 \mathrm{~g} / \mathrm{mL}$ in PB-Tween, were added to the odd-numbered columns of the plate. The even-numbered columns, which acted as paired control wells, were filled with $150 \mu \mathrm{L}$ PB-Tween. The experimental plate setup is shown in Figure 5, and two identical plates were used, allowing for a total of six simultaneous experiments. The plate was then covered and allowed to incubate at room temperature for $1.5 \mathrm{~h}$. Following the incubation period, the plate was washed with PB-Tween using the washing procedure described in Table 1.
The next step was the addition of HRP, followed by the detection of the amount of enzyme captured. An initial concentration of HRP was added to wells A1 and its paired control A2, A5 and control A6, and A9 and control A10. The remainder of the wells was filled with PB-Tween. Using doubling dilutions, the enzyme was then diluted down the well strips, and then the solution was brought back to the top of the plate for another set of doubling dilutions. This yielded a total of 16 dilutions of the initial HRP solution (Table 5). After the enzyme had been added, the plate was covered and allowed to stand at room temperature for $1 \mathrm{~h}$. The standard washing procedure was then performed. The amount of HRP captured on the antibody-immobilized wells and the paired control wells was evaluated using the ELISA protocol with the ABTS substrate described above.

\section{RESULTS AND DISCUSSION}

\section{Biotinylated Enzyme Immobilization}

Biotinylated enzyme immobilization results are given in Figure 6 in the form of kinetic plots for the eight assays performed on the two plates. Each data point is the average of eight values. Before plotting, the data were ana- lyzed for outlying points. This analysis was performed using the rigorous rejection quotient (Q) test (21). This test allowed for the removal of erroneous data with $90 \%$ confidence. The assays presented in Figure 6 show that the extent of binding of bHRP to the silver ion surface is considerably higher than the extent of binding to either the amine or GT surfaces. Combining the data from Plate 1 and Plate 2, it was possible to perform a statistical analysis using exact sampling theory and Student's $t$ distribution to assign $95 \%$ confidence limits to the data. This analysis shows that the silver ion surface is unique in its ability to immobilize biotinylated compounds. This property is derived from the addition of silver ions alone because the unmodified amine surface and the modified GT surface are statistically indistinguishable. Therefore, the microplate activation procedure does not alter the plate surface or the ability of the plate to bind proteins. It is only when the silver ions are immobilized in the wells that the plate becomes activated and is capable of binding biotinylated compounds.

To determine the detection limit of the silver ion system for bHRP, a statistical analysis on the low concentration end of the analysis in Figure 6 was performed. It can be seen that the detection of bHRP in the silver ion wells is statis-

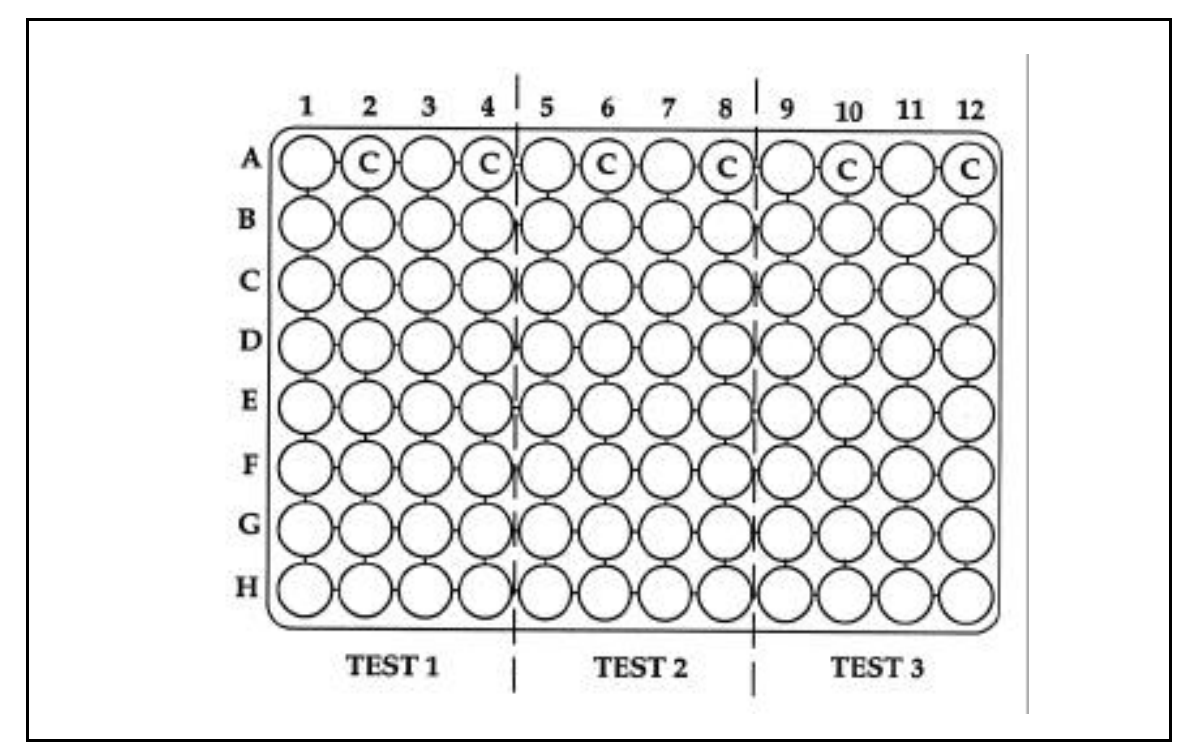

Figure 5. A schematic diagram illustrating the antibody immobilization assay microplate configuration. Triplicate results are conducted on each microplate. The stripwells designated with the letter $\mathrm{C}$ are control wells. Two separate microplates are used to generate the data shown in Figure 9. 


\section{Research Report}

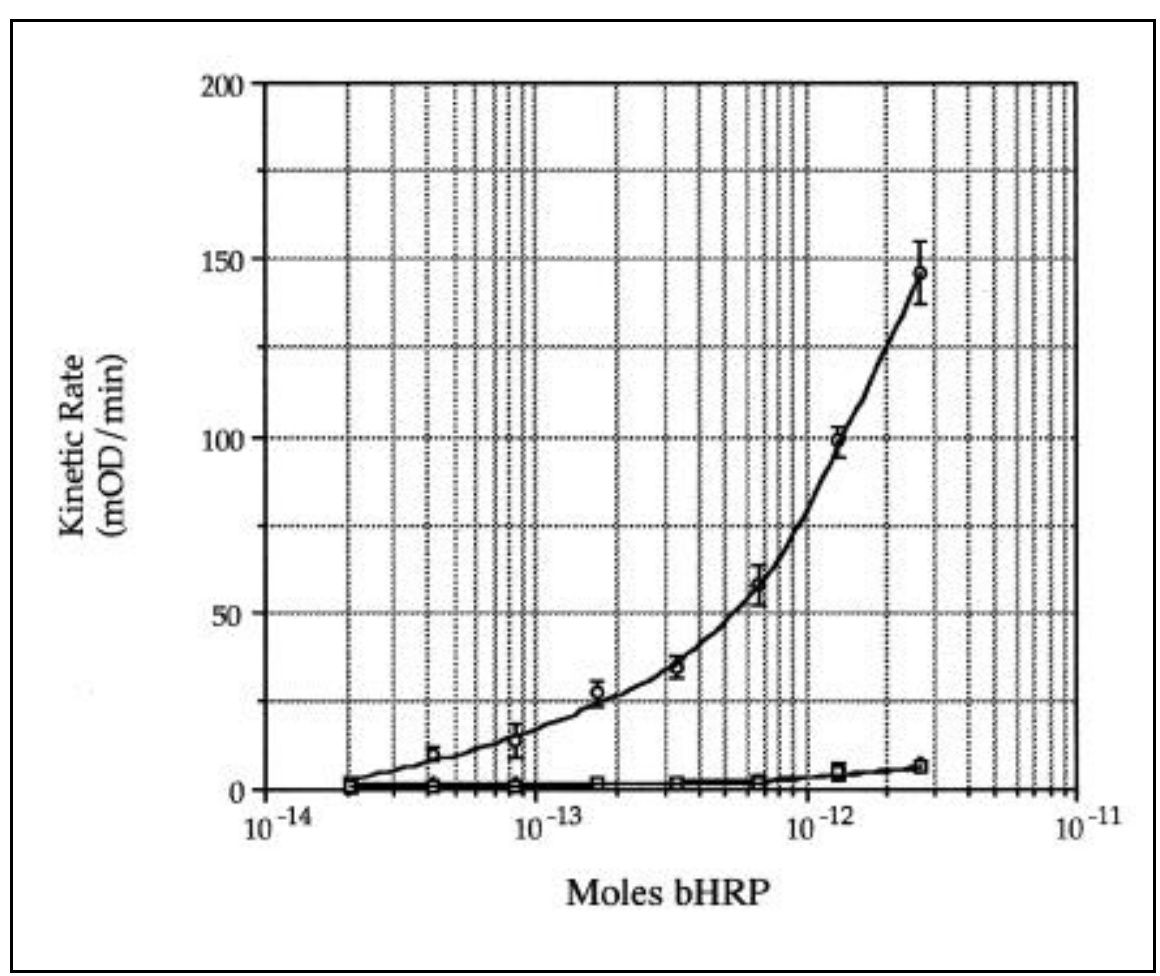

Figure 6. Detection of the amount of bHRP immobilized onto the surface of the microplate well. The open circles represent data for microwells coated with silver ions. The filled triangles (blocked by the open squares) represent the data for microwells coated with glutaraldehyde and thiourea but containing no silver ions. The open squares represent the data for the unmodified microwells containing surface amine groups.

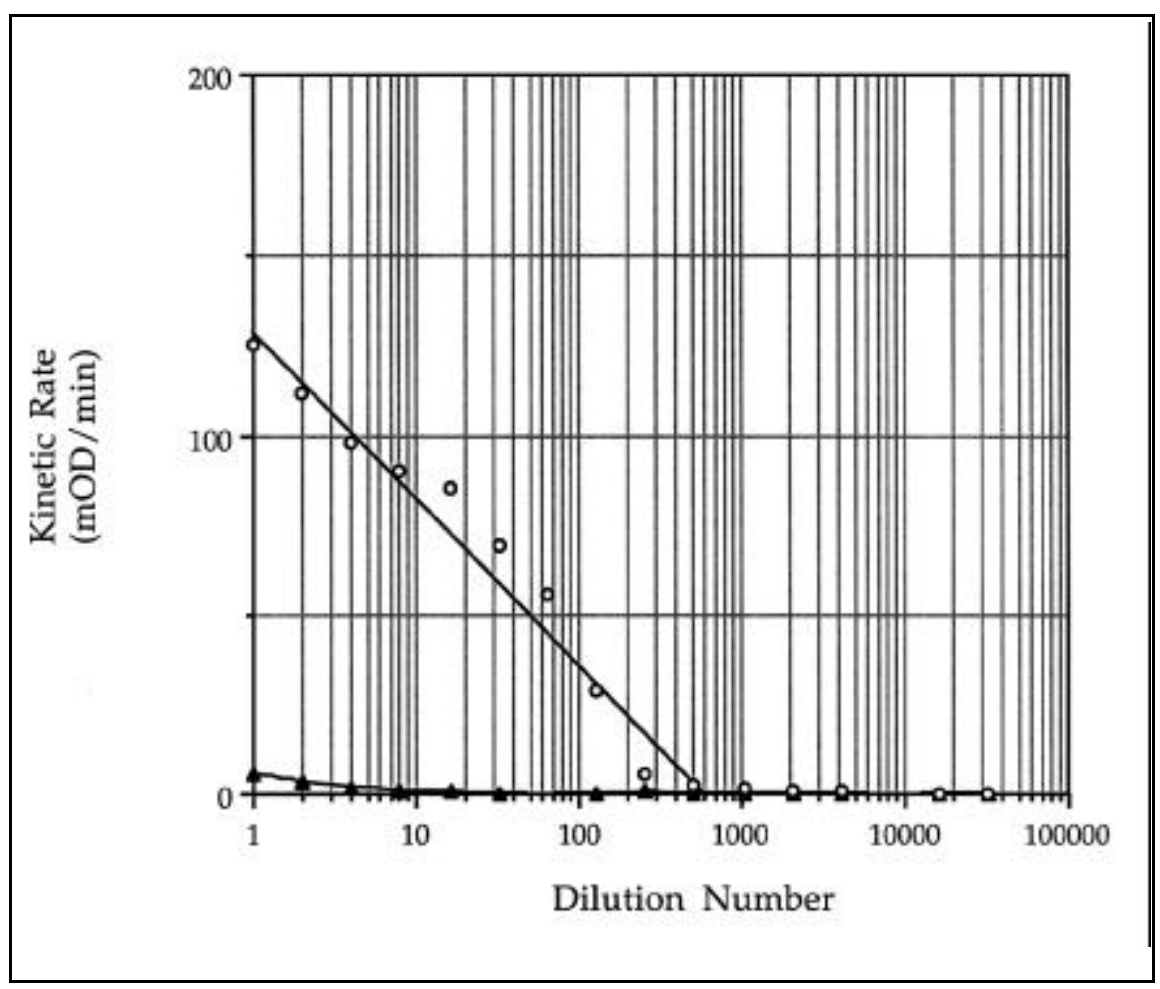

Figure 7. Comparison of HRP and bHRP binding to microplates using silver ion coating. The circles represent the bHRP data, while the filled triangles are the data for the unlabeled enzyme (HRP). tically distinct from the control wells until the last dilution. From Table 2, it can be determined that the detection limit is at least $40 \mathrm{fmol}$.

The results of the binding comparison between biotin-labeled and unlabeled HRP are shown in Figure 7. Since two tests were performed for both bHRP and HRP, the values in the graph are the average of these runs. Figure 7 was plotted as a function of dilution number, as this allows standardization between experiments that have varying initial concentrations of the target analyte. It can be seen that the unlabeled enzyme exhibited little binding to the silver ion plates, while the biotinylated enzyme bound as seen before. The preferential immobilization of the bHRP to the silver ion-coated wells can therefore be attributed to the biotin label.

Improvements in immobilization technology for proteins and enzymes are aimed at increasing the density of binding sites, providing strong coupling to the surface, and yielding proper orientation to maintain their bioactivity (28). The specific bHRP activity for degradation of ABTS under our experimental conditions was determined to be $2.9 \times$ $10^{-5} \mathrm{M} / \mathrm{min} / \mathrm{mg}$ enzyme (9). Using a microplate optical path length of $0.5 \mathrm{~cm}$ and a molar absorptivity for oxidized ABTS of $36.8 \mathrm{mM} / \mathrm{cm}$, the kinetic rate data in Figure 6 can be analyzed to determine an affinity equilibrium constant and the saturation surface concentration. From a plot of the data, we determined that $\mathrm{K}_{\mathrm{m}}=8 \times 10^{9} / \mathrm{M}$ and that the maximum immobilization density is 40 $\mathrm{ng} / \mathrm{cm}^{2}$ (which corresponds to a molecular area of $180 \mathrm{~nm}^{2} /$ molecule) for bHRP using silver ion-coated microplates. These values compare favorably with values for antibody immobilization (20) where immobilization densities of $74-220 \mathrm{ng} / \mathrm{cm}^{2}$ (molecular areas of 110-340 $\mathrm{nm}^{2} /$ molecule) are reported. A commercially available streptavidin-coated plate gives a biotinylated species density of $33 \mathrm{~nm}^{2} /$ molecule (5), which compares well with the theoretical maximum monolayer coverage of streptavidin (39 $\mathrm{nm}^{2} /$ molecule). Metal ion coatings of $\mathrm{Ni}(\mathrm{II}), \mathrm{Cu}(\mathrm{II}), \mathrm{Co}(\mathrm{II})$, $\mathrm{Ca}(\mathrm{II})$ and $\mathrm{Zn}$ (II) for microplates are also available (http://www.xenopore. com). Ni(II)-coated microplates are reported to have a capacity of $9 \mathrm{pmol} /$ well 


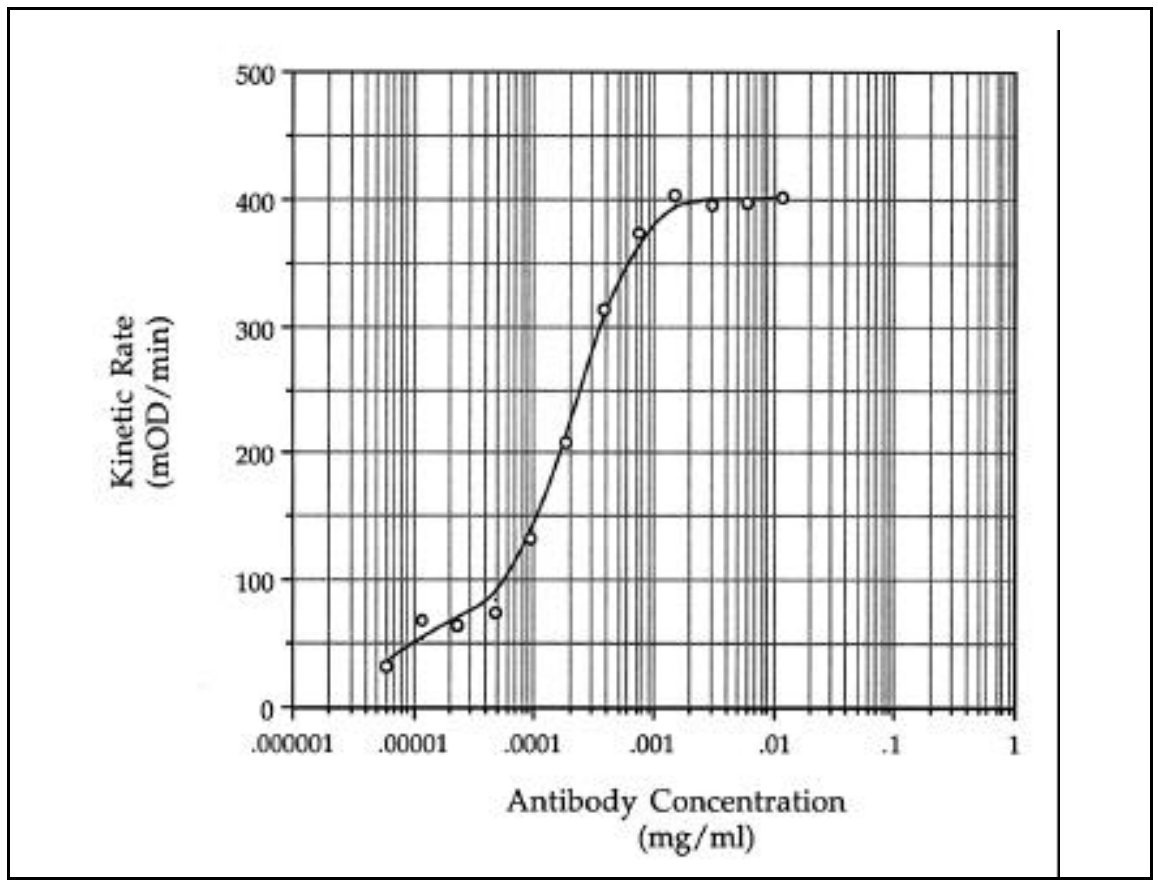

Figure 8. Initial rate data $\left(10^{-3}\right.$ absorbance units/min) for diagonal test array well strip $\mathrm{H} 1$ through H12. The HRP enzyme, which is captured by the immobilized anti-HRP antibody, oxidizes ABTS, yielding a chromogenic product. The amount of enzyme captured is proportional to the rate of increase in the absorbance at $415 \mathrm{~nm}$. Initial added concentrations of anti-HRP antibody greater than or equal to 0.0015 $\mathrm{mg} / \mathrm{mL}$ yield the maximum amount of enzyme that can be captured from an initial added quantity of 0.2 $\mathrm{pmol} / \mathrm{well}$.

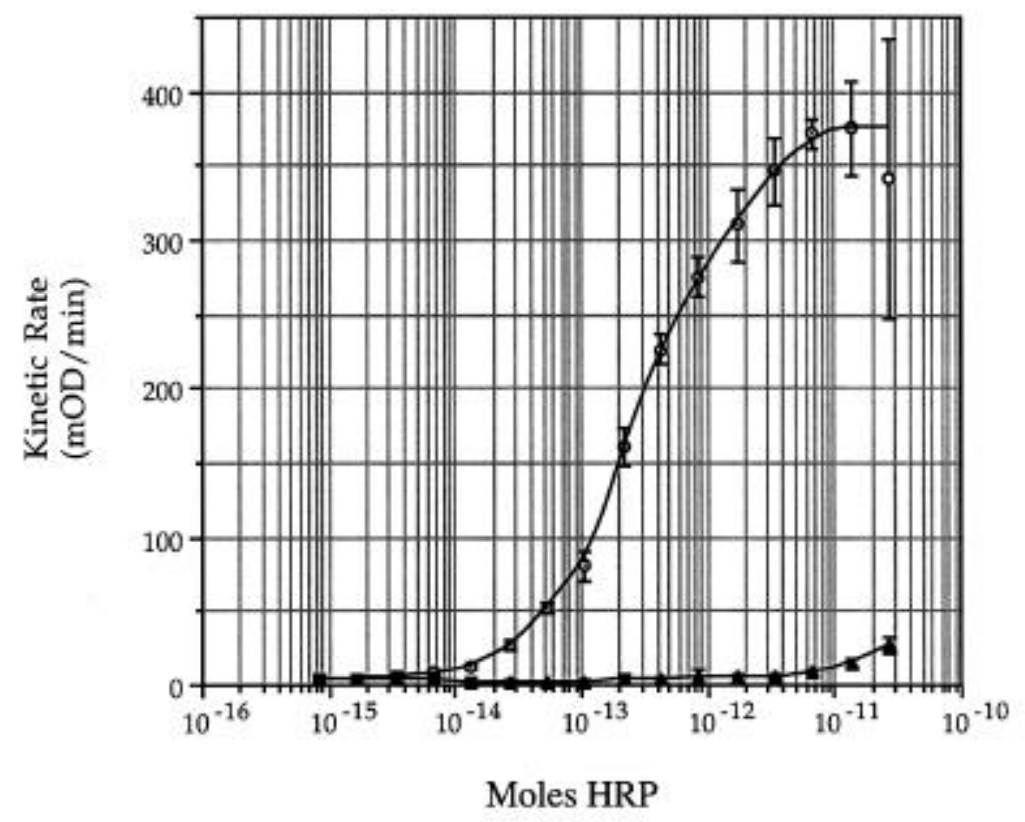

Figure 9. Results of the antibody immobilization assay illustrated in Figure 5. The amount of antibody immobilized is detected indirectly by the rate of change in absorbance because of the sequence of HRP capture and enzyme assay using ABTS. The modified silver ion microplate with immobilized anti-HRP antibody can detect enzyme amounts greater than $6.7 \mathrm{fmol}$. Based on the maximum absorbance rate of 0.375 absorbance units/min, the surface density of anti-HRP is estimated to be between 130 and $260 \mathrm{~nm}^{2} /$ antibody molecule. The data provided also indicate the background levels of HRP binding for modified silver ion microplates. The open circles refer to data for modified silver ion microplates exposed to biotinylated anti-HRP antibodies. The closed triangles refer to data for silver ion microplates with no added antibody. for attaching a histidine-tagged peptide, which suggests a molecular area of approximately $20 \mathrm{~nm}^{2} /$ molecule. This illustrates the higher surface loading possible with metal ions as universal linkers as compared to protein linkers such as streptavidin. Interestingly, $\mathrm{Ni}$ (II) metal ions show virtually no affinity for biotinlabeled proteins (http://www.xenopore. com), which is expected based on metal ion affinity chromatography studies.

\section{Capture Antibody Immobilization}

For antibody immobilization, the data in Figure 8 agree with the expected trends of the diagonal assay. The highest amount of enzyme capture occurs in the top left region of the plate, which contains the highest initial concentration of both antigen and enzyme. The least amount of enzyme captured occurs in the lower right region of the plate because the lowest initial concentrations of antibody and enzyme are present in this region. To determine the minimum antibody concentration, which is still effective in capturing the most enzyme possible for a given initial amount of HRP, the data from Row $\mathrm{H}$ on the microplate were analyzed. This data, presented in Figure 8, shows the effect of varying the antibody concentration on the capture of a constant initial amount of HRP.

As can also be seen in Figure 8, the initial dilutions of the antibody solution are capable of binding equal amounts of HRP. From an initial concentration of $0.012 \mathrm{mg} / \mathrm{mL}$ antibody down to an initial concentration of $0.0015 \mathrm{mg} / \mathrm{mL}$, the amount of enzyme captured is essentially the same. However, any further decrease in initial antibody concentration drastically lowers the amount of enzyme captured. Thus, the minimum initial concentration used to assay for HRP using this particular antibody is $0.0015 \mathrm{mg} / \mathrm{mL}$.

With the data from the checkerboard assay, more extensive enzyme capture experiments could be performed. Figure 9 shows the results of an enzyme capture assay, where each point is the average of six observations. The $95 \%$ confidence limits were calculated according to a statistical procedure for small sample numbers (1). The kinetic rate was calculated by subtracting the 


\section{Research Report}

rate found in the paired control wells from the rate determined in the experimental wells. This operation accounts for nonspecific binding of the HRP to the plate surface.

As Figure 9 shows, the silver ion format is extremely sensitive and is capable of detecting as little as $6.7 \times 10^{-15} \mathrm{~mol}$ HRP. The capture assay also shows relatively high fidelity because nearly all of the error bars are small. However, because the first dilution has a high amount of HRP and, hence, the antibody sites are saturated, the error bar is large because two relatively large numbers are subtracted to obtain a smaller number.

The binding of HRP in the wells of the silver ion plate is also extremely specific, as can be seen in Figure 9. The data in Figure 9 are not corrected for background binding. Wells containing only immobilized silver ions are used as control wells. Nonspecific binding of this enzyme to the silver ion control wells occurs only at the highest levels of HRP.

Because of the recent interest in the employment of antibodies in biosensors, there has been a flurry of activity in the development of new antibody immobilization methods. Immobilization of antibodies onto gold surfaces using thiol-containing molecules attached to the $\mathrm{Fc}$ region has been demonstrated by several groups (10, 17). Polymer coatings have also been used $(12,13)$, with one recent study showing that antibodies can be attached using electrostatic interactions (25). Similar to the silver ion immobilization method used in this work (1), glutaraldehyde has been used as a linking step for attachment of antibodies to amine-coated surfaces for a surface plasmon resonance sensor chip (19).

Of importance to the biosensor investigators cited above is that a surface be created that has a high density of active antibody and very low nonspecific binding. For the capture antibody microplates developed in this work (based on a specific bHRP activity for degradation of ABTS under the experimental conditions used of $2.9 \times 10^{-5} \mathrm{M} / \mathrm{min} /$ mg enzyme (9), a microplate optical path length of $0.5 \mathrm{~cm}$, and a molar absorptivity for oxidized ABTS of 36.8 $\mathrm{mM} / \mathrm{cm}$ ) the estimated active antibody density is $130-260 \mathrm{~nm}^{2} /$ antibody molecule depending on whether a $1: 1$ or $2: 1$ enzyme:antibody binding ratio is achieved. This range compares favorably with antibody molecular surface densities of 110-340 $\mathrm{nm}^{2} /$ molecule (20) using heterobifunctional crosslinkers, although, with this technique, as many as $50 \%$ of the antibody sites were not active. A comparison of HRP capture by anti-HRP antibodies with commercially available streptavidincoated microplates (1) showed that the silver ion-coated microplates have 2.5 times the capture capacity.

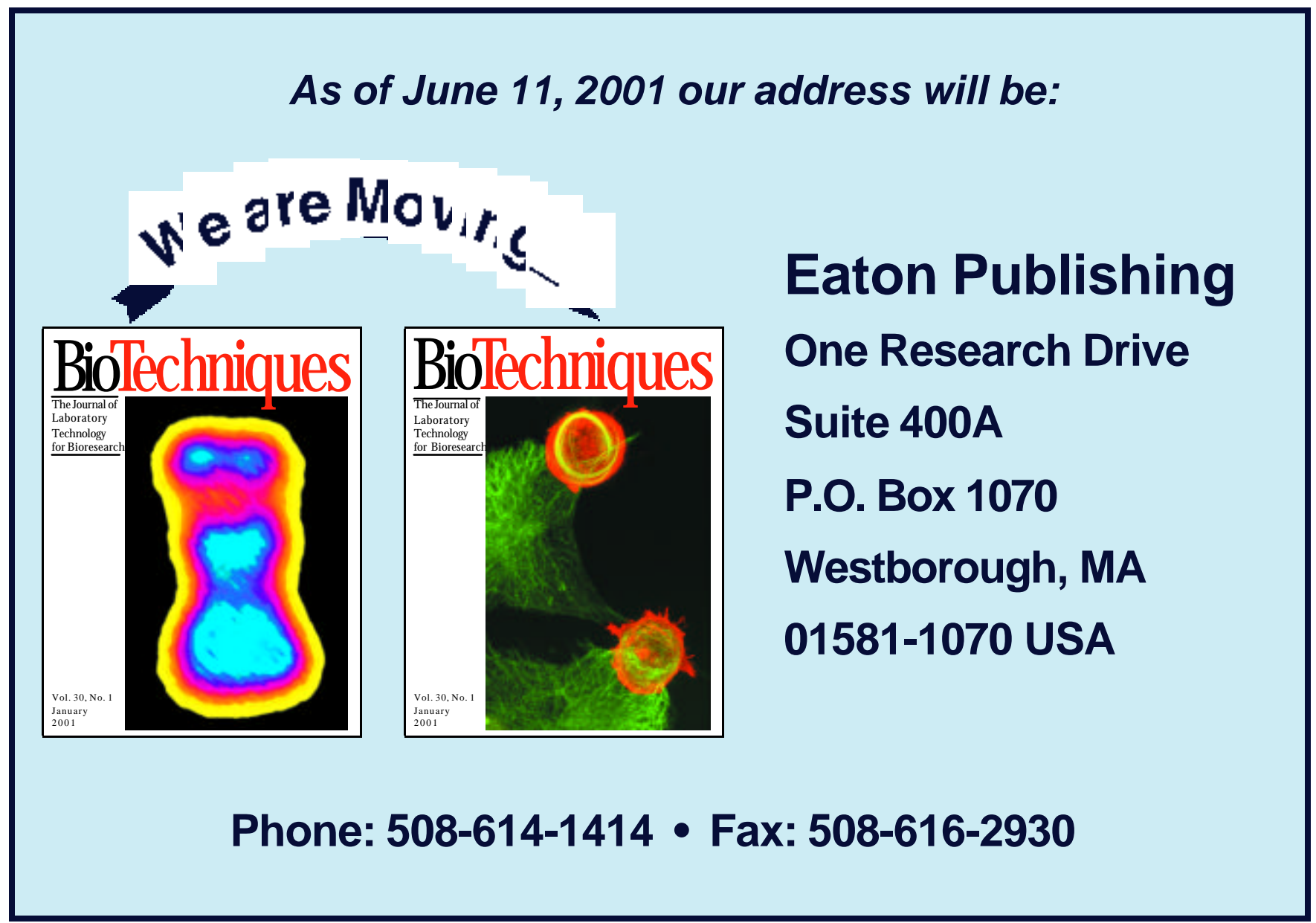




\section{CONCLUSIONS}

A new coating for microplates is useful for immobilizing biotin-labeled enzymes and antibodies. Comparative studies with HRP and its biotin-labeled counterpart show that the silver ion coating complexes with biotin to immobilized the enzyme onto the surface of the microwells.

Biotin-labeled antibodies can be im mobilized on the surface of the wells of microplates using silver ions coated on the inner surface of the wells. The surface silver ions are coordinated with thiourea functional groups, leaving them active for chemical complexation with biotin molecules linked to the Fc region of antibodies. By immobilizing an anti-HRP antibody, the sensitivity of the HRP capture assay was found to be in the femtomole range for the silver ion-modified microplates. Background binding of HRP to the modified silver ion microplate without the presence of the antibody was found to be very low at HRP levels below 10 pmol. Even at the highest HRP quantity of 30 pmol, the background was only $7 \%$ of the average signal. The modified silver ion microplate is estimated to yield an active antibody surface density of 130-260 nm²/antibody molecule.

This new coating complements currently available specialty-coated microplates that have transition metal ions such as $\mathrm{Zn}(\mathrm{II}), \mathrm{Cu}(\mathrm{II})$, and $\mathrm{Co}(\mathrm{II})$ ions on their surfaces for immobilizing histidine-tagged proteins. Because of the smaller footprint of metal ions, higher surface densities of immobilized peptides could be achieved as compared to streptavidin-coated microplates.

\section{ACKNOWLEDGMENTS}

The authors would like to thank the National Science Foundation for supporting this research.

\section{REFERENCES}

1.Bonen, M.R. 2000. Immobilized Silver Ions as The Basis of a Highly Sensitive Microplate Immunoassay System. Ph.D. Dissertation, Arizona State University, Tempe.

2.Butler, J.E., L. Ni, R. Nessler, K.S. Joshi, M. Suter, B. Rosenberg, J. Chang, W.R.
Brown, and L.A. Cantarero. 1992. The physical and functional behavior of capture antibodies adsorbed on polystyrene. J. Im munol. Methods 150:77-90.

3.Deshpande, S.S. 1996. Enzyme Immunoassays: From Concept to Product Development, Chapman \& Hall, New York.

4.Diamandis, E.P. and T.K. Christopoulos. 1991. The biotin-(strept)avidin system: principles and applications in biotechnology. Clin. Chem. 37:625-636.

5.Douglas, A.S. and C.A. Monteith. 1994. Im provements to immunoassays by covalent binding assay plates. Clin. Chem. 40:18331837.

6.Foster, K. 1996. Microtiter plate-based enzyme immunoassay: the universal format system, p. 277-309. In D.W. Chan (Ed.), Im munoassay Automation: An Updated Guide to Systems. Academic Press, San Diego.

7.García, A.A., D.-H. Kim, and D.R. Miles. 1994. Immobilization of silver and platinum ions for metal affinity chromatography. Reactive Polymers 23:249-259.

8.Green, N.M. 1960. Avidin and streptavidin. Methods Enzymol. 184:51-67.

9.Jaya, M. 2000. The Interaction of Palladium (II) Ions Immobilized onto Paramagnetic Particles with Biotin-Labeled and Unlabeled Horseradish peroxidase, M.S. Thesis, Arizona State University, Tempe.

10.Kanno, S., Y. Yanagida, T. Haruyama, E. Kobatake, and M. Aizawa. 2000. Assem bling of engineered IgG-binding protein on gold surface for highly oriented antibody im mobilization. J. Biotechnol. 76:207-214.

11.Kim, D.-H. and A.A. García. 1995. Retention behavior of amino acids using immobilized Ag(I) chromatography. Biotechnol. Progr. 11:465-467.

12.König, B. and M. Gratzel. 1993. Development of a piezo electric immunosensor for the detection of human erythrocytes. Anal. Chim. Acta 276:329-333.

13.Lin, Z.H., G.L. Shen, Q. Miao, and R.Q. Yu. 1996. A thyroid-stimulating hormone im muno-electrode. Anal. Chim. Acta. 325:8792.

14.Miles, D.R. and A.A. García. 1995. Separation of biotin labeled proteins from their unlabeled counterparts using immobilized platinum affinity chromatography. J. Chromatogr. A 702:173-179.

15.Odell, W.D., J. Griffin, and R. Zahnradnik. 1986. Two-monoclonal-antibody sandwichtype assay for thyritropin, with use of an avidin-biotin separation technique. Clin. Chem. 32:1873-1878.

16.O'Shannessy, D.J. 1990. Antibodies biotinylated via sugar moieties. Methods Enzymol. 184:162-166.

17.Park, I.-S. and N. Kim. 1998. Thiolated salmonella antibody immobilization onto the gold surface of piezoelectric quartz crystal. Biosensors Bioelectronics 13:1091-1097.

18.Ramírez-Vick, J.E. 1997. Recovery of Biotin-Labeled Oligonucleotides Using Paramagnetic Particles with Silver(I) as a Soft Metal Ligand. Ph.D. Dissertation, Arizona State University, Tempe.

19.Sasaki, S., R. Nagata, B. Hock, and I. Karube. 1998. Novel surface plasmon reso- nance sensor chip functionalized with organic silica compounds for antibody attachment. Anal. Chim. Acta 368:71-76.

20.Shriver-Lake, L.C., B. Donner, R. Edelstein, K. Breslin, S.K. Bhatia, and F.S. Ligler. 1997. Antibody immobilization using heterobifunctional crosslinker. Biosensors Bioelectronics 12:1101-1106.

21.Spiegel, M.R. 1961. Theory and Problems of Statistics. McGraw-Hill, New York.

22.Suter, M. and J.E. Butler. 1986. The im munochemistry of sandwich ELISAs II. A novel system prevents the denaturation of capture antibodies. Immunol. Lett. 13:313-316.

23. Wilchek, M. and E.A. Bayer. 1984. The avidin-biotin complex in immunology. Im munol. Today 5:39-43.

24.Wilchek, M. and E.A. Bayer. 1988. The avidin-biotin complex in bioanalytical applications. Anal. Biochem. 171:1-32.

25.Wu, Z., Y. Yan, G. Shen, and R. Yu. 2000. A novel approach of antibody immobilization based on n-butyl amine plasma-polymerized films for immunosensors. Anal. Chim. Acta 412:29-35.

26. Yalow, R.S. and S.A. Berson. 1959. Assay of plasma insulin in human subjects by immunological methods. Nature 184:1648-1649.

27.Yalow, R.S. and S.A. Berson. 1960. Im munoassay of endogenous plasma insulin in man. J. Clin. Invest. 39:1157-1175.

28.Zhang, J. and A.E.G. Cass. 2000. Electrochemical analysis of immobilised chemical and genetic biotinylated alkaline phosphatase. Anal. Chim. Acta 408:241-247.

Received 19 June 2000; accepted 22 November 2000.

Address correspondence to:

Dr. Antonio A. García

Department of Bioengineering

Arizona State University

Tempe, AZ 85287-6006, USA

e-mail: tony.Garcia@asu.edu 